\title{
Altruism, fast and slow? Evidence from a meta-analysis and a new experiment
}

\author{
Hanna Fromell ${ }^{1} \cdot$ Daniele Nosenzo $^{2,3}$ iD $\cdot$ Trudy Owens $^{3}$
}

Received: 30 November 2018 / Revised: 15 January 2020 / Accepted: 22 January 2020 /

Published online: 25 February 2020

(c) The Author(s) 2020

\begin{abstract}
Can we use the lens of dual-system theories to explain altruistic behavior? In recent years this question has attracted the interest of both economists and psychologists. We contribute to this emerging literature by reporting the results of a meta-study of the literature and a new experiment. Our meta-study is based on 22 experimental studies conducted with more than 12,000 subjects. We show that the overall effect of manipulating cognitive resources to promote the "intuitive" system at the expense of the "deliberative" system is very close to zero. One reason for this null result could be that promoting intuition has heterogeneous effects on altruism across different subgroups of subjects or contexts. Another reason could be that there simply is no real effect and that previously reported single results are false positives. We explore the role of heterogeneity both by performing a mediator analysis of the meta-analytic effect and by conducting a new experiment designed to circumvent the issue of potential heterogeneity in the direction of the effect of promoting intuition. In both cases, we find little evidence that heterogeneity explains the absence of an overall effect of intuition on altruism. Taken together, our results offer little support for dual-system theories of altruistic behavior.
\end{abstract}

Keywords Altruism · Giving · Dictator game · Dual-system model · Intuition · Deliberation $\cdot$ Self-control $\cdot$ Willpower $\cdot$ Depletion $\cdot$ Stroop task

\section{JEL Classification C91}

Electronic supplementary material The online version of this article (https://doi.org/10.1007/s1068 3-020-09645-z) contains supplementary material, which is available to authorized users.

Daniele Nosenzo

daniele.nosenzo@liser.lu; daniele.nosenzo@nottingham.ac.uk

Extended author information available on the last page of the article 


\section{Introduction}

A recent literature in economics and psychology argues that human behavior can be understood as the interaction between two different decision systems (Kahneman 2002, 2011): one that is fast, intuitive, automatic and largely effortless ("System 1"), and one that is slower, more deliberate, and requires some level of reflection and cognitive effort ("System 2"). For some decisions, the two systems may diverge in the choices they favor: while deliberation may pull the individual towards a certain choice (e.g., keeping a healthy diet), intuition may pull them towards a different choice (e.g., eating tasty but highly caloric food). In these cases, an individual must use willpower and spend cognitive resources to override the intuitive impulse and take the choice favored by the deliberative system.

It has been suggested that altruistic behavior can also be rationalized by this dual-system framework (Loewenstein and O'Donoghue 2007; Moore and Loewenstein 2004; Zaki and Mitchell 2013; Deck and Jahedi 2015; Dreber et al. 2016). One of the most debated questions in this literature is whether altruism (and pro-social behavior more generally) is a spontaneous and intuitive response, where individuals must use willpower if they wish to act in their self-interest; or whether instead self-interest is intuitive, and individuals must use willpower to behave pro-socially.

A number of experiments have been designed to address this question. These experiments rely on different types of manipulations, designed to inhibit one of the systems and promote the other. For example, subjects in an experiment may be asked to distribute an amount of money between themselves and another participant (e.g., in a dictator game), while at the same time performing another task that is more or less cognitively-taxing (e.g., holding a 7-digit or 3-digit number in their memory). Compared to subjects who perform the easier task, subjects who perform the hard task are under "cognitive load": they have fewer cognitive resources to devote to the dictator game decision, and are therefore less able to use their deliberative system when deciding how much to give to the other participant. Other commonly used types of manipulations include: "ego depletion" where subjects participate in a sequence of two tasks, the first to deplete cognitive resources, and the second to measure how the consequent reduced ability to use deliberation affects behavior; "time pressure" where subjects are forced to make a decision either quickly or after having deliberated for some time; and "priming" where subjects are consciously or subconsciously encouraged to decide using either their intuitive or deliberative system.

In this paper, we report a meta-analysis of the experimental studies that have used cognitive load, ego depletion, time pressure, and priming to study the effects of promoting intuition on altruistic behavior. Our meta-study covers 22 papers involving a total of 60 experiments and more than 12,000 subjects. We find that in $57 \%$ of the experiments, promoting intuition leads to more self-interested behavior, suggesting that self-interest is an intuitive response. In the other $43 \%$ of experiments promoting intuition encourages more altruistic behavior, suggesting that altruism, and not self-interest, is intuitive. These effects, however, are 
statistically significant only in a minority of studies. In the large majority of cases (78\% of experiments), the effect of promoting intuition is insignificantly different from zero. The overall effect size estimated across all 60 experiments is only -0.015 , and we cannot reject the null hypothesis that this is actually zero.

It is unclear how to interpret this evidence. On the one hand, taken at face value, the fact that the literature has found effects in either direction, and an average estimated effect close to zero, may suggest that the true underlying effect is actually very small or non-existent, and that the few significant effects reported in the literature are false positives. That is, altruism is neither fast nor slow: this type of behavior simply escapes the logic of the dual-system framework.

On the other hand, some researchers have argued that whether intuition favors altruism or self-interest may depend on a variety of individual, social, and contextual factors. While for some subgroups of individuals in some specific situations intuition may favor altruism, for other subgroups or situations intuition may favor self-interest (e.g., Hauge et al. 2016; Rand et al. 2016; Grossman and Van der Weele 2017; Balafoutas et al. 2018). That is, the mixed results reported in the literature could simply reflect a genuine heterogeneity in the underlying decision processes that different individuals use in different situations-and since this heterogeneity is typically unanticipated and unaccounted for in most existing studies, this could explain why the reported overall effect is small and close to zero in most of the literature.

To assess the role of heterogeneity in explaining the mixed results found in the literature, we conduct a mediator analysis to identify factors that may account for systematic differences across studies in the size and direction of the effect of intuition on altruism. We examine a variety of factors that have been proposed in the literature as possible mediators of the effect, including gender (Rand et al. 2016), the frame of the game (Hauge et al. 2016; Banker et al. 2017; Gärtner 2018), and the experimental stakes (Mrkva 2017; Andersen et al. 2018). With the possible exception of the frame of the game, for which we find mixed support, we find no evidence that any of the factors we consider can explain the variance in effect sizes across studies. For gender, a previous meta-analysis by Rand et al. (2016) found that promoting intuition has significantly different effects for women and men: the effect is positive and significant for women, but negative and insignificant for men. If anything, our analysis, which subsumes most of Rand et al.'s data and is based on a much larger number of studies, finds the opposite: the effect is negative for both women and men (significantly so only for the latter), and we cannot reject the null of no difference in the size of the effect between genders.

These results lend little support to the argument that there may be a genuine heterogeneity in the size and direction of the effect of intuition on altruism across different subsamples and that this may explain the mixed evidence reported in the literature about the overall effect of intuition on altruism. To further probe this conclusion, in the last part of the paper we report a new experimental test of the hypothesis that altruistic behavior responds to the logic of the dual-system model. While existing studies have tested this hypothesis by studying whether promoting System 1 makes individuals more altruistic or more self-interested, we examine whether making choices that involve a trade-off between altruism and self-interest triggers 
a conflict between the two systems that is cognitively taxing and willpower-depleting. An advantage of our experimental test is that, unlike existing experiments, it is robust to the presence of heterogeneity in whether System 1 favors altruism or selfinterest. Even if System 1 is altruistic for some individuals and self-interested for others, both types of subjects would have to spend willpower to regulate a conflict between self-interest and altruism, as long as System 1 and 2 diverge in the behavioral motive that they favor. We do not find evidence that facing a trade-off between self-interested and altruistic choices depletes willpower. Taken together the results from our meta-study and our new experiment offer little support for a dual-system theory of altruistic behavior.

The remainder of this paper is structured as follows. In Sect. 2 we present the findings of our meta-analysis of the existing literature. Section 3 describes the design and results of the new experiment. Section 4 concludes.

\section{Meta-study}

\subsection{Design}

We searched the literature for experimental studies investigating the effect of promoting intuition on altruistic behavior. We include studies that use one of the four standard types of interventions to promote intuition at the expense of deliberation (cognitive load, ego depletion, time pressure, or priming), and that assess the effect of these interventions of individuals' decisions to distribute wealth between themselves and another passive player. ${ }^{1}$ The passive player can be another participant in the experiment (as in standard dictator games), or a charitable organization (as in donation experiments). In all cases, the decisions must involve a trade-off between the decision-maker's and passive player's payoffs (i.e., we exclude settings in which the decision-maker can increase the passive player's payoff at no cost for themselves; or cases where the choice that maximizes the decision-maker's payoff also maximizes the passive player's payoff). We require that the study adheres to the methodology of experimental economics (i.e., no deception), and that decisions have real monetary consequences for the parties involved (i.e., no hypothetical studies). For more details on the selection process, see Appendix A in the Online Supplementary Materials (OSM).

\footnotetext{
${ }^{1}$ The proliferation of studies using cognitive resources manipulations has triggered a number of recent meta-studies of these literatures. For example, Rand (2016), Kvarven et al. (2019), and Rand (2019) assess the role of intuition and deliberation in cooperation decisions. Verschuere et al. (2018) study the role of cognitive load interventions on lying. Rand et al. (2016) — discussed in more detail below—study how the interaction between gender and intuition shapes dictator game decisions.
} 
Based on our inclusion criteria, the meta-study covers 22 studies involving 60 experiments conducted with a total of 12,574 subjects across 12 countries. ${ }^{2}$ About half of the experiments were run with university students, a third with Amazon Mechanical Turk (AMT) workers, and the rest with other specific non-student samples, for instance junior school students or members of the general population. About two-thirds of experiments involved some type of dictator game decision (where the passive players are other experiment participants), while the rest involved a charitable donation decision. Table A.1 lists all included studies and the number of experiments each study contributed to the meta-study. ${ }^{3}$

For each experiment, we quantified the effect that promoting intuition had on altruistic behavior by calculating the standardized mean difference (Cohen's $d$ ) in altruism between the experimental condition that promoted intuition and the condition that promoted deliberation. ${ }^{4}$ In most cases, we measured altruism as the monetary amount (or fraction of endowment) that the decision-maker gives to the passive player; in studies involving binary dictator decisions, we used the fraction of decision-makers sacrificing own payoff to increase the passive player's payoff. ${ }^{5}$ In all cases, a positive effect size indicates that individuals became more altruistic when intuition was promoted, relative to the condition that promoted deliberation. In contrast, a negative effect size indicates that promoting intuition made individuals more self-regarding.

\subsection{Results}

Figure 1 contains a forest plot showing, for each of the 60 experiments included in our study, the associated effect size and $95 \%$ confidence interval. ${ }^{6}$ The figure is

\footnotetext{
${ }^{2}$ Rand et al. (2016) also conducted a meta-analysis of the literature on the role of intuition in dictator game decisions, with the special focus on gender as mediator of the main effect. Their study covers 22 experiments involving 4366 subjects. Rand and colleagues kindly shared their dataset with us, and we therefore include in our meta-study all experiments covered in their analysis, with the exception of 4 experiments from 2 studies that involve deception. In addition, our meta-analysis includes another 19 studies (42 experiments, 8472 subjects) that were not included in Rand et al.'s meta-study.

${ }^{3}$ In most cases, a single study contains more than one treatment (or was run in more than one location), hence most studies contribute more than one experiment each to the meta-study.

${ }^{4}$ Formulas are provided in Appendix A. We apply Hedges' correction for small sample bias to calculate effect sizes and associated standard errors (see Lipsey and Wilson 2001).

5 The information required to perform these calculations was retrieved either from the statistics, graphs and tables reported in the papers, or from data made available by the authors (marked by * in Table A.1). In some cases, the analyses reported in the papers are based on subsets of the data collected (e.g. only using subjects who are compliant to the time pressure manipulation; or only using subjects who pass an attention check). Wherever possible we base our meta-analysis on the full datasets-i.e. including all subjects for which there are data, regardless of the exclusion criteria used in the original papers. See Appendix A for further details.

${ }^{6}$ The $95 \%$ confidence intervals reported in the meta-study are computed as $E S \pm 1.96 * S E^{E S}$ where $E S$ is the effect size (Cohen's $d$ ), $S E^{E S}$ is the standard error of the effect size estimate, and 1.96 is the z-score for the 97.5 percentile point of the normal distribution. Wherever in the paper we make statements such as "the $95 \%$ confidence interval of the effect size includes zero" we simply mean that we cannot reject the null that the effect size is zero. See Morey et al. (2016) for a discussion of the fallacies in interpreting confidence intervals in frequentist statistics.
} 


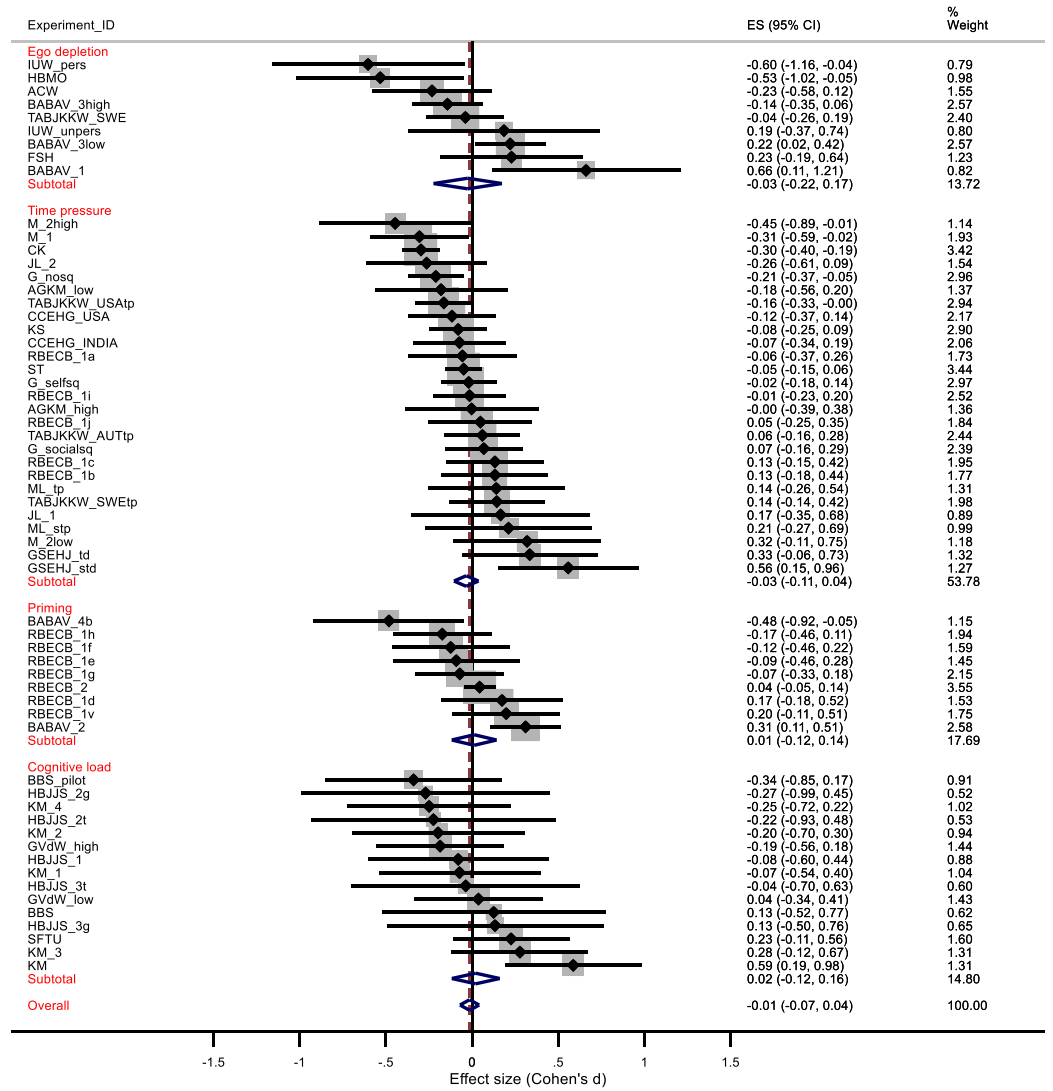

Fig. 1 Results of the random-effects meta-analysis of promoting intuition on altruism. Note: Effect sizes (ES) measured as standardized mean difference in altruism between conditions where intuition or deliberation were promoted. Positive values imply more altruism in the intuitive condition. Error bars indicate $95 \%$ confidence intervals. The size of the grey boxes indicates the weight of the effect size in the metaanalysis (the relative weights are also reported in the last column of the figure). In each panel of the figure, the row labeled "Subtotal" reports the average effect size for each type of intervention, estimated by the random-effects meta-analysis model. The last row of the figure (labeled "Overall") reports the average effect size across all experiments and its associated confidence interval. For a legend of the experiment IDs refer to Table A.1 in the OSM

divided into four panels, one for each type of intervention included in the metastudy. In each panel, the bottom row reports the average effect size and associated confidence interval of each intervention, estimated using a random-effects metaanalysis model. The last row of the figure reports the overall effect size estimated across all four types of interventions.

For each type of intervention, there are experiments associated with both negative and positive effect sizes. Across the four types of interventions, 57\% of experiments report a negative effect of promoting intuition, while the remaining $43 \%$ report a positive effect. In most cases, however, the $95 \%$ confidence interval of the effect size includes zero. Only in 13 out of 60 experiments (22\% of cases) does the confidence 
interval not contain zero: in 8 cases the estimated effect size is negative, and in the remaining 5 cases it is positive.

As a consequence, the average effect size of each type of intervention is very small and not different from zero at the $5 \%$ significance level or lower: 0.021 for cognitive load studies $(p=0.766),-0.034$ for time pressure studies $(p=0.349),-0.025$ for ego depletion studies $(p=0.803)$, and 0.012 for priming studies $(p=0.858)$. Across all types of interventions, the overall effect size is -0.015 , with an associated $95 \%$ confidence interval of $[-0.070,0.041]$. We cannot reject the null that the overall effect size is actually zero $(\mathrm{z}=0.51, p=0.607)$.

Based on these results, what should we conclude about the role of intuition and deliberation for altruistic behavior? The face-value interpretation of our findings is that promoting intuition has only a very small (if any) effect on altruistic choices. Thus, one may conclude that the logic of the dual-system model does not extend to altruistic behavior.

However, several researchers have suggested that the mixed evidence concerning the overall effect of promoting intuition on altruism may reflect a genuine heterogeneity in the size and direction of the effect across different subgroups of the population, or across different decision settings. That is, the researcher may observe no aggregate effect of the intervention on altruistic behavior, when in fact the manipulation may have led a subgroup of subjects to become more altruistic and another subgroup to become more self-regarding-with the two opposing effects cancelling each other out in the aggregate.

Rand et al. (2016) for instance, propose that what is automatized as an intuitive response depends on the strategies that are typically advantageous in one's daily social interactions. They argue that what constitutes a socially advantageous strategy may vary across individuals or groups, and propose that gender may be an important moderating factor in the case of altruism: altruism may be an intuitive social response for women, but less so for men. Other researchers have argued that the underlying pro-social inclinations of the individual may moderate the effect of intuition on altruism: while altruism may be an intuitive response for pro-social types, the opposite may be true for self-interested types (e.g., Balafoutas et al. 2018; Chen and Krajbich 2018). Moreover, some researchers have focused on contextual and situational factors as possible mediators of the effect of promoting intuition on altruism. Andersen et al. (2018) and Mrkva (2017), for instance, examine the role of experimental stakes. Banker et al. (2017) propose that there is an interaction between the effect of promoting intuition and whether the decision situation uses a "giving" or "taking" frame: in the former case, manipulations that promote intuition may decrease altruism, while in the latter case they may increase altruism.

However, because the evidence of heterogeneous effects inevitably relies on multiple tests of the same hypothesis (e.g., separate tests among men and women of the hypothesis that intuition promotes altruism), a potential concern is that some of the reported heterogeneous effects may actually be false positives rather than reflect a genuine heterogeneity in the effect for different subgroups or contexts. The problem may be exacerbated in cases where the multiple comparisons are the result of data-dependent analyses, a phenomenon that has been referred to as "forking" (e.g., Gelman and Loken 2013). Moreover, the problem may be further amplified when 
the reported heterogeneous effects are discovered by aggregating data from several studies that contain false-positive results, as it may be the case in "internal metaanalyses" where inferences are based on the aggregated analysis of multiple experiments reported in the same paper (Vosgerau et al. 2018).

In the next section, we use the meta-study to assess the extent to which various individual and situational factors discussed in the literature can explain the variance in effect sizes across experiments included in our analysis. The advantage of this approach is that we can test the role of each factor by relying on information from papers that did not necessarily focus on that factor to organize their own data. For instance, we can test the hypothesis that intuition promotes altruism among women but not among men, by combining data from studies that did and did not analyze the effect disaggregated by gender. Since we can rely on information from variables that the original authors may not have used in their analysis or publication decisions, this approach potentially mitigates the bias introduced by data-dependent analyses.

\subsection{Mediator analysis}

We examine the extent to which the effect of promoting intuition on altruism may be moderated by a long list of factors discussed in the literature, namely: the role of gender; the type of intervention used to manipulate cognitive resources; the frame of the game (give or take); the nature of the passive player (another participant or a charity); the stakes used in the experiment, the type of subject pool used to conduct the study (e.g., students, AMT workers, etc.); and the location where the experiment was run. For each factor, we conduct a random-effects meta-regression where the dependent variable is the effect size detected in the experiment, and where each experiment is weighted by the inverse of its variance so that more precise studies have more influence in the analysis. The regressions for these variables (with the exception of gender, discussed below) are reported in Table 1.

The last two columns of Table 1 report specifications where all mediators are simultaneously included in the regression. In column (7) we include study dummies-not reported in the table-to account for study fixed effects (these are also included in all regressions of columns 1-6), while in column (8) we report a specification without study fixed effects (see Table A.3 in the OSM for versions of regressions 1-6 without study fixed effects). There are advantages and disadvantages to either specification. The study fixed-effects specification exploits within-study variation in the mediators of interest, controlling for potential unobservable idiosyncrasies of the individual studies (e.g., specific characteristics of the subject pool used in a given study). This is a very clean form of identification, especially for variables that the researcher has randomized at the study level (e.g., take or give frame treatments). However, the large number of study dummies (22) compared to the relative small number of observations (60) raises potential concerns about overfitting. Moreover, removing the study fixed-effects allows to exploit between-study variation in the mediators of interest, which, as discussed earlier, is valuable if one is concerned that the choice of treatments within a study may have been partly datadriven. As we show below, although estimates vary between the two approaches, 
Table 1 Mediator analysis: random-effects meta-regressions

\begin{tabular}{|c|c|c|c|c|c|c|c|c|}
\hline Variable & (1) & (2) & (3) & (4) & (5) & (6) & (7) & (8) \\
\hline Stakes & $\begin{array}{l}0.004 \\
(0.006)\end{array}$ & & & & & & $\begin{array}{l}0.003 \\
(0.006)\end{array}$ & $\begin{array}{l}-0.002 \\
(0.004)\end{array}$ \\
\hline 1 if students & & $\begin{array}{l}0.119 \\
(0.150)\end{array}$ & & & & & $\begin{array}{l}0.069 \\
(0.202)\end{array}$ & $\begin{array}{l}0.026 \\
(0.094)\end{array}$ \\
\hline 1 if AMT workers & & $\begin{array}{l}-0.146 \\
(0.123)\end{array}$ & & & & & $\begin{array}{c}-0.109 \\
(0.140)\end{array}$ & $\begin{array}{l}-0.082 \\
(0.102)\end{array}$ \\
\hline 1 if exp. run in USA & & & $\begin{array}{l}-0.140 \\
(0.232)\end{array}$ & & & & $\begin{array}{l}-0.168 \\
(0.252)\end{array}$ & $\begin{array}{c}-0.179 \\
(0.095)\end{array}$ \\
\hline 1 if exp. run in Europe & & & $\begin{array}{l}0.064 \\
(0.271)\end{array}$ & & & & $\begin{array}{l}-0.011 \\
(0.340)\end{array}$ & $\begin{array}{c}-0.180 \\
(0.101)\end{array}$ \\
\hline 1 if donation game & & & & $\begin{array}{l}0.003 \\
(0.371)\end{array}$ & & & $\begin{array}{l}0.171 \\
(0.385)\end{array}$ & $\begin{array}{l}-0.021 \\
(0.083)\end{array}$ \\
\hline 1 if take frame & & & & & $\begin{array}{l}0.266 \\
(0.145)\end{array}$ & & $\begin{array}{l}0.292 \\
(0.168)\end{array}$ & $\begin{array}{l}0.298^{\text {**** }} \\
(0.102)\end{array}$ \\
\hline 1 if cognitive load & & & & & & $\begin{array}{c}-0.040 \\
(0.318)\end{array}$ & $\begin{array}{l}-0.016 \\
(0.328)\end{array}$ & $\begin{array}{l}0.042 \\
(0.093)\end{array}$ \\
\hline 1 if ego depletion & & & & & & $\begin{array}{l}0.008 \\
(0.230)\end{array}$ & $\begin{array}{l}-0.107 \\
(0.236)\end{array}$ & $\begin{array}{l}-0.165 \\
(0.100)\end{array}$ \\
\hline 1 if priming & & & & & & $\begin{array}{c}-0.049 \\
(0.123)\end{array}$ & $\begin{array}{c}-0.053 \\
(0.128)\end{array}$ & $\begin{array}{l}0.070 \\
(0.083)\end{array}$ \\
\hline Study FE? & Yes & Yes & Yes & Yes & Yes & Yes & Yes & No \\
\hline N. effect sizes & 60 & 60 & 60 & 60 & 60 & 60 & 60 & 60 \\
\hline N. experiments & 60 & 60 & 60 & 60 & 60 & 60 & 60 & 60 \\
\hline N. subjects & 12,574 & 12,574 & 12,574 & 12,574 & 12,574 & 12,574 & 12,574 & 12,574 \\
\hline
\end{tabular}

Dependent variable is the effect size associated to an experiment

the two identification strategies lead to the same conclusions in all but one case (the effect of the frame of the game).

Stakes Some authors have argued that whether intuition favors altruism or selfinterest depends on the amount of money at stake in the decision situation. For instance, Mrkva (2017) argues that when stakes are high, an individual's impulsive response is to reject a request for money, and that generosity may thus be fostered by deliberation, while the reverse may happen when stakes are low. The stake level is defined as the maximum payoff available to the decision-maker (e.g. in a dictator game, the endowment received by the dictator), converted in 2017 USD PPP and multiplied by the probability that this amount is actually paid to the subject (in several studies not all choices made by subjects are paid with certainty, either because the study uses role uncertainty or because the giving decision is part of a set of tasks and the random lottery incentive system is used). ${ }^{7}$ Column (1) of Table 1 reports the

\footnotetext{
${ }^{7}$ In three cases (one experiment of Mrkva 2017 and two experiments of Banker et al. 2017), the papers did not report sufficient information about the probability with which each choice was paid. In these cases, we assumed that the stakes were similar to those used in the other experiments reported in those papers.
} 
regression results. We do not find any significant association between stake level and effect size $(p=0.522)$. We find the same result in the regressions of columns (7) and (8), where we control for other mediators. We conclude that stakes are not a significant mediator of the effect of intuition on altruism.

Sample In column (2) we investigate whether there is heterogeneity in the effect sizes associated with different types of samples with which the experiments were run (students, AMT workers, etc.). The base category in the regression are studies run with non-student samples that are not AMT workers. We do not detect any significant differences between the base category (n. experiments $=7$ ) and AMT workers $(n=20)$ or students $(n=33)$. We also do not find any significant difference between AMT workers and students (F-test: $p=0.129)$. This is also true for the regressions in columns (7) and (8).

Location of the experiment In column (3) we explore whether the location where the experiment was run affects the estimate of the effect size. About half of the experiments were run in the US $(n=31)$, about a third in Europe $(n=23)$, while the rest in other countries such as Chile, India, Israel or Tunisia (the base category in the regression, $n=7) .{ }^{8}$ We do not detect any difference between experiments run in Chile, India, Israel or Tunisia and those run in the US or Europe, nor do we find a difference between Europe and the US (F-test: $p=0.151)$. The same holds for the regressions in columns (7) and (8).

Charity as passive player About a third of experiments were based on donation games $(n=17)$, where decision-makers decide how much money to donate to a charitable organization. We do not find that the effect sizes in these studies differ from those reported in the dictator game experiments, as shown in columns (4), (7) and (8).

Frame of the game Banker et al. (2017) argue that the framing of the decision situation plays an important role in determining whether altruism or self-interest are an intuitive response. This is because intuition may favor choices that are salient. When the choice involves taking money that has been initially allocated to the passive player, the salient cue is to leave the amount with the passive player, and therefore promoting intuition will lead to more altruism. The reverse may happen when the choice involves giving money that has been initially allocated to the decision-maker. Gärtner (2018) entertains a similar hypothesis. Hauge et al. (2016) also report games with either give or take frames. In column (5) we test whether experiments using a take frame $(n=8)$ are associated with larger effect sizes (indicating more altruism in the intuitive condition) than experiments using a give frame. The coefficient of the take frame dummy is indeed positive but not significantly different from zero at the $5 \%$ level or lower $(p=0.074)$. The same holds in column (7) $(p=0.093)$. However, in column (8), where we do not control for study fixed effects and exploit both within- and between-study variation in the frame of the game, we find a statistically significant positive effect $(p=0.005)$. Based on these analyses, we

\footnotetext{
${ }^{8}$ One experiment (Chen and Krajbich 2018) used a subject pool comprised of individuals from Germany and the US, and we cannot separate subjects based on nationality. This is why both the USA and EU dummies are coded as 1 for this experiment.
} 
Table 2 Mediator analysis: the role of gender

\begin{tabular}{lllll}
\hline Variable & $(1)$ & $(2)$ & $(3)$ & $(4)$ \\
\hline 1 if female & 0.052 & 0.054 & 0.054 & 0.053 \\
& $(.041)$ & $(.041)$ & $(.049)$ & $(.044)$ \\
Study FE? & Yes & Yes & No & No \\
Additional controls? & No & Yes & No & Yes \\
N. effect sizes & 100 & 100 & 100 & 100 \\
N. experiments & 50 & 50 & 50 & 50 \\
N. subjects & 10,728 & 10,728 & 10,728 & 10,728 \\
\hline
\end{tabular}

Random-effects meta-regressions. Dependent variable is the effect size associated to an experiment. The additional controls are the other mediators examined in Table 1

tentatively suggest that the frame of the game might be a mediator of the effect of intuition on altruism, although more research on this specific factor seems warranted given the mixed results.

Type of intervention In column (6) we test whether there are systematic differences between the effect sizes reported in studies that use different types of manipulation of cognitive resources. For instance, one may hypothesize that some types of manipulations (e.g. priming manipulations that prompt participants to consider the positive effects of "carefully reasoning through a problem") may be more prone to demand effects than others, and thus promote a stronger effect. We thus include dummies for experiments relying on cognitive load $(n=15)$, ego depletion $(n=9)$, and priming $(\mathrm{n}=9)$, with time pressure experiments $(\mathrm{n}=27)$ as the base category. ${ }^{9}$ We do not find any difference between types of manipulation, in any of the possible bilateral comparisons (all $p>0.690$ ). The same holds for the regressions in columns (7) and (8).

Gender Rand et al. (2016) propose that gender is an important mediator of the role of intuition and deliberation on altruism. They argue that altruism may be an intuitive response for women more than for men. In their meta-study, they indeed find a significant difference between effect sizes for men and women. Moreover, in line with their hypothesis, they find that the estimated effect size is positive and significant for women, while negative and insignificant for men (they use 5\% as the probability of type-I error in their study, as we do in this paper).

For nearly all studies in our meta-analysis we can compute separate effect sizes for men and women and thus re-test the hypothesis put forward by Rand et al. (2016) with a much larger sample than they had available in their meta-study (50 experiments involving 10,728 subjects compared to 22 experiments and 4366 subjects in Rand et al.). Table 2 reports random-effect meta-regressions based on the subsample of experiments for which we can compute gender-specific effect sizes.

\footnotetext{
${ }^{9}$ In one case (Tinghög et al. 2016), the manipulation relies on a combination of cognitive load and ego depletion and hence we code both dummies as 1 for this experiment.
} 
In column (1) we only include a gender dummy as well as study dummies to control for study fixed effects, while in column (2) we also add the mediators listed in Table 1 as additional controls. In columns (3) and (4) we report analogous specifications but without study fixed effects. In all cases, we only detect a small difference between effect sizes for men and women, which is not statistically significant $(p>$ 0.193).

Figure 2 further illustrates this result. It contains forest plots showing the effect sizes and $95 \%$ confidence intervals of the 50 experiments used in the gender analysis. The top panel of the figure shows the forest plot for men, while the bottom panel shows the plot for women. The last row of each panel reports the overall effect size estimated across all experiments.

In either case the gender-specific effects sizes are quite small. For men, the overall effect size is negative $(-0.079)$ and we can reject the null that the effect size is not zero at the $1 \%$ level $(p=0.002)$. For women, the overall effect size is also negative $(-0.008)$, but not different from zero at any conventional level of significance $(p=0.843)$. Thus, our results are in contrast with the findings reported by Rand et al. (2016), who found that promoting intuition increases altruistic behavior among women, but has no effect among men. ${ }^{10}$

Note that the sample we used to conduct the gender analysis differs in two ways from Rand et al.'s sample: we have added 32 experiments from 17 studies that were not available to Rand et al. at the time of their meta-analysis, and we have excluded 4 experiments from 2 studies that Rand et al. had included, because they involved deception. Is the difference in results between our meta-analysis and Rand et al.'s due to the addition of new studies, or to the exclusion of the studies that involved deception? We repeated the analysis above using only the studies included in Rand et al. except those that involved deception. We can replicate Rand et al.'s results in this subsample: for men the overall effect size is negative $(-0.078)$, but insignificant at the $5 \%$ level or lower $(p=0.087)$, while for women the overall effect size is positive $(0.135)$ and significant $(p=0.003)$. We then performed the analysis using only the new studies that were not available to Rand et al. In this case, the effect size is negative for both men $(-0.066)$ and women $(-0.070)$, and insignificantly different from zero at the $5 \%$ significance level or lower for either group ( $p=0.063$ for men; $p=0.139$ for women). Thus, the difference in results is due to the addition of the 32 experiments that were not included in Rand et al. ${ }^{11}$

Taken together, our results lend little support to the argument that there may be genuine heterogeneity in the size and direction of the effect of intuition on altruism across different subsamples, and that this may explain the mixed evidence reported in the literature about the overall effect of intuition on altruism. We think that the

\footnotetext{
10 However, given the mixed evidence on the role of gender for moderating the effect of intuition on altruism, it is entirely possible that our result and Rand et al.'s result are both false positives. We would therefore invite caution in drawing conclusions from this finding (also see Vosgerau et al. 2018 for a discussion of the perils of false positive results in internal and external meta-analyses).

11 Five of the new studies are based on donation games between a decision-maker and a charity. We checked whether the inclusion of these studies affects our results, but found no evidence that this is the case.
} 


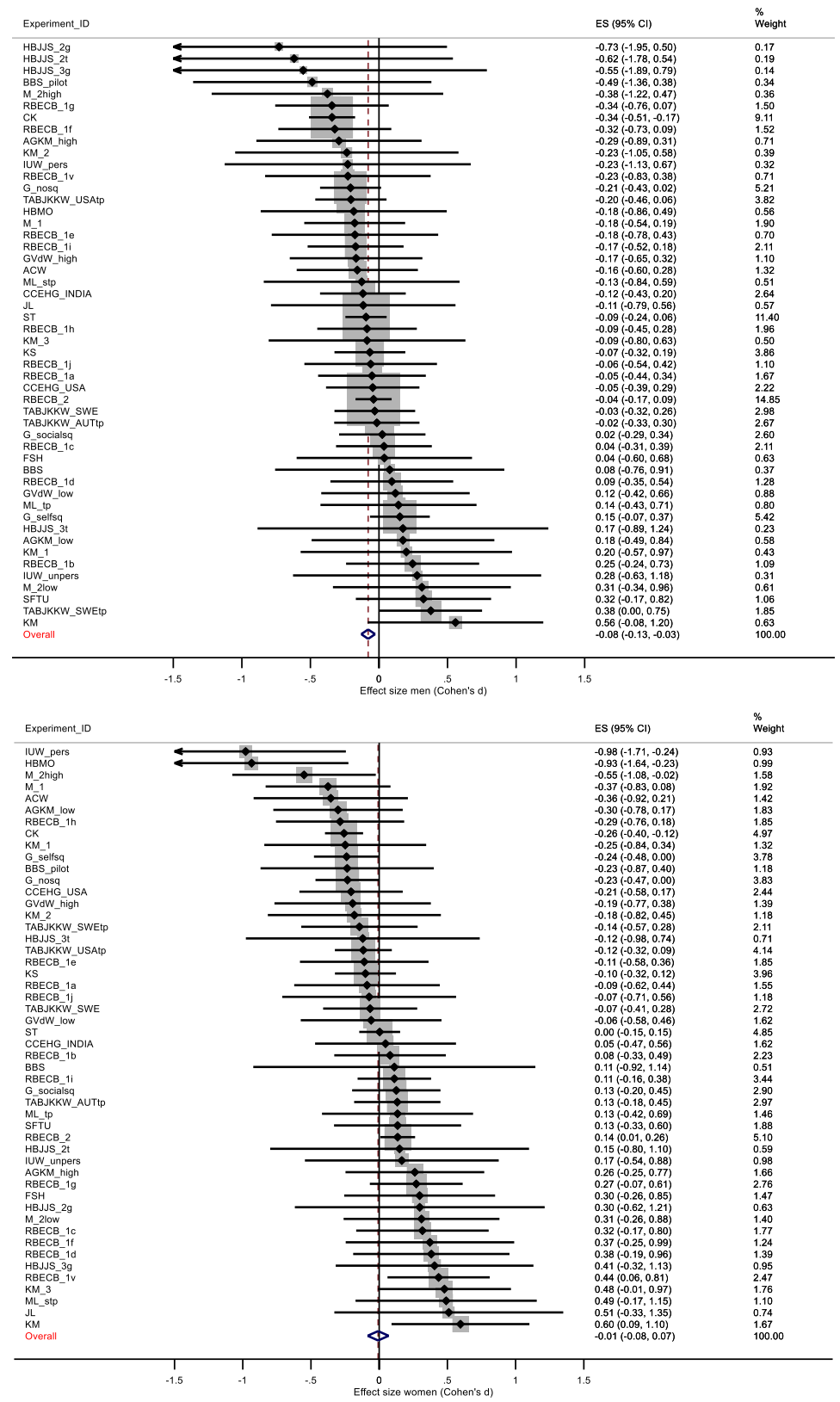

Fig. 2 Effect sizes for men (top panel) and women (bottom panel). Note: Effect sizes (ES) measured as standardized mean difference in altruism between conditions where intuition or deliberation were promoted. Positive values imply more altruism in the intuitive condition. Error bars indicate $95 \%$ confidence intervals. The size of the grey boxes indicates the weight of the effect size in the meta-analysis (the relative weights are also reported in the last column of the figure). The last row of the figure (labeled "Overall") reports the average effect size across all experiments and its associated confidence interval. For a legend of the experiment IDs refer to Table A.1 in the OSM 
most likely explanation for the conflicting evidence reported in previous studies (and reproduced in our meta-analysis) is that this actually reflects contrasting false positive results. To further probe this conclusion, in the next section we report results from a novel experimental paradigm that, as we explain below, may allow to identify the effect of intuition on altruism even in the presence of heterogeneity in the direction of the effect triggered by the manipulation of cognitive resources.

\section{New experiment}

The starting point of our experimental design is the observation that, if choices that involve trade-offs between altruism and self-interest trigger a conflict between intuition and deliberation, then individuals exposed to such trade-offs will have to consume cognitive resources and willpower to regulate this conflict. Note that this is true regardless of whether one's theory proposes that altruism is intuitive and self-interest deliberate, or whether it proposes instead that self-interest is intuitive and altruism deliberate. In the former case, willpower is required to rein in the prosocial impulse; in the latter it serves to override the selfish impulse. In either case, the individual will have to use willpower when they face decisions that involve a trade-off between altruism and self-interest. In other words, these trade-offs are willpower-depleting.

This implies a straightforward prediction: individuals exposed to trade-offs between altruism and self-interest will have less willpower available for subsequent tasks that also require the use of willpower. A crucial advantage of this prediction is that it holds irrespective of whether altruism or self-interest are intuitive: it only requires that the intuitive process diverges from the deliberate process so that a conflict between the two systems arises. Therefore, the presence of heterogeneity in the direction of the effect does not constitute a problem. Even if intuition promotes selfinterest for a subgroup of subjects while it promotes altruism for another subgroup, both subgroups will experience a conflict when exposed to trade-offs between altruism and self-interest, and this will affect the cognitive resources that both types of subjects have access to in subsequent tasks.

\subsection{Experimental design}

We test this prediction in a new experiment where we reverse the order of tasks typically used in ego depletion experiments: we use a series of 16 dictator games as the first, willpower-depleting task; and a second cognitively-demanding and willpower-requiring task (a version of the Stroop 1935 color-word task)" to be consistent with the way citations appear when parentheses are used elsewhere in the paper, to measure the effect of participating in the dictator games on residual willpower.

In the first task, subjects were randomly matched in pairs to participate in the 16 dictator games shown in Table 3. In each pair, one subject was allocated the role of dictator and the other the role of recipient. Pairs and roles were kept fixed 
Table 3 Payoffs in the binary dictator games

\begin{tabular}{|c|c|c|c|c|}
\hline \multirow[b]{2}{*}{ Game } & \multicolumn{2}{|l|}{ Conflict } & \multicolumn{2}{|c|}{ NoConflict } \\
\hline & Option A & Option B & Option A & Option B \\
\hline 1 & $8 ; 8$ & $12 ; 0$ & $8 ; 0$ & $12 ; 8$ \\
\hline 2 & $11 ; 1$ & $8 ; 8$ & $11 ; 8$ & $8 ; 1$ \\
\hline 3 & $9 ; 1$ & $7 ; 5$ & $9 ; 5$ & $7 ; 1$ \\
\hline 4 & $7 ; 5$ & $8 ; 2$ & $7 ; 2$ & $8 ; 5$ \\
\hline 5 & $10 ; 6$ & $12 ; 0$ & $10 ; 0$ & $12 ; 6$ \\
\hline 6 & $8 ; 8$ & $16 ; 0$ & $8 ; 0$ & $16 ; 8$ \\
\hline 7 & $6 ; 6$ & $8 ; 4$ & $6 ; 4$ & $8 ; 6$ \\
\hline 8 & $10 ; 2$ & $9 ; 7$ & $10 ; 7$ & $9 ; 2$ \\
\hline 9 & $12 ; 0$ & $6 ; 6$ & $12 ; 6$ & $6 ; 0$ \\
\hline 10 & $11 ; 5$ & $15 ; 1$ & $11 ; 1$ & $15 ; 5$ \\
\hline 11 & $8 ; 4$ & $10 ; 2$ & $8 ; 2$ & $10 ; 4$ \\
\hline 12 & $9 ; 3$ & $8 ; 4$ & $9 ; 4$ & $8 ; 3$ \\
\hline 13 & $10 ; 6$ & $8 ; 8$ & $10 ; 8$ & $8 ; 6$ \\
\hline 14 & $13 ; 3$ & $10 ; 6$ & $13 ; 3$ & $10 ; 3$ \\
\hline 15 & $6 ; 6$ & $8 ; 2$ & $6 ; 2$ & $8 ; 6$ \\
\hline 16 & $10 ; 0$ & $6 ; 4$ & $10 ; 4$ & $6 ; 0$ \\
\hline
\end{tabular}

In each game, dictators could choose between two options, A or B, each implying a different distribution of money between themselves and the recipient. For each option, the first number indicates the dictator's payoff and the second number the recipient's payoff (both displayed in GBP). In both treatments, the 16 games were presented to subjects in the same order as shown in the table

across the 16 games. Across two between-subject treatments, we manipulated the extent to which the dictator games required exertion of willpower by varying the structure of payoffs of the games. In the 16 games of our Conflict treatment, the option that maximized the dictator's payoff always minimized the recipient's payoff. Thus, in this treatment dictators faced a series of trade-offs between selfinterested and altruistic choices, as is customary in standard dictator games. In our NoConflict treatment, we removed this trade-off by manipulating payoffs so that the option that maximized the dictator's payoff also maximized the recipient's payoff. 
In both treatments, subjects then participated in a version of the Stroop (1935) color-word task, which is often used to measure willpower depletion. ${ }^{12}$ Subjects were shown, for five minutes, a series of words of color names printed in various font colors. Both color names and font colors were either black, blue, green, red, or yellow. The font colors and color names were randomly matched so that, for each word, the font color did not correspond to the color name. Subjects had to indicate, for each word, which color it was printed in, and not the color that the word read. ${ }^{13}$ This task requires regulation of choice because, in order to submit a correct answer, subjects must override their intuitive and automatic impulse to respond by reading the color name of the word, and look at its font color instead. Thus, the task demands continuous exertion of willpower by the participant to regulate the conflict that arises between their intuitive and deliberative systems.

If willpower is a resource that can be depleted with use (Muraven and Baumeister 2000; Baumeister et al. 2007), and if the 16 games of the Conflict treatment require more use of willpower than the corresponding games of NoConflict, then we would expect dictators in Conflict to arrive at the Stroop task with less residual willpower than those in NoConflict, and therefore to be comparatively less able to expend further willpower during the Stroop task. In Sect. 3.3, we test this hypothesis by comparing the number of correct answers given by dictators in the Stroop task between our two treatments.

Note that the crucial assumption underlying our test is that the trade-offs faced by dictators in the 16 games of the Conflict treatment trigger a series of motivational conflicts that are depleting in terms of willpower, whereas such conflicts (and hence willpower depletion) do not arise in the NoConflict treatment. The rationale for this assumption is based on recent findings from the depletion literature that making choices, particularly choices that involve large trade-offs between options, is costly in terms of willpower. Vohs et al. (2008), for instance, show that even mundane, small-cost choices (e.g., choosing between different colored t-shirts) cause willpower depletion as measured in a series of tasks that require exertion of self-control (e.g., making oneself drink an unsavory beverage; or submerging one's arm in cold water). Spears (2011) reports analogous findings using a Stroop-like task to measure willpower depletion. Moreover, Wang et al. (2010) show that choices involving large trade-offs are more depleting than choices involving small trade-offs. These findings suggest that, to the extent that dual-system theories extend to altruistic behavior, the

\footnotetext{
12 See MacLeod (1991) for a review of studies using the Stroop task. In dual-task studies, the Stroop task has been used both as a task to measure willpower depletion and as a willpower-depleting task. Hagger et al. (2010) show that the task is particularly sensitive to willpower depletion relative to other commonly used tasks (e.g. math or mental arithmetic or solvable anagrams) and thus is well suited as a dependent measure. There is some evidence that the task is instead less effective when used as a willpower-depleting instrument (Hagger et al. 2010; Carter et al. 2015). In the economics literature, the Stroop task has been predominantly used as a willpower-depleting task to study, for example, the effects of willpower depletion on procrastination (Burger et al. 2011), sensitivity to framing effects (De Haan and Van Veldhuizen 2015) and time preferences (Kuhn et al. 2014).

13 For instance, if the word "green" was printed in blue, the correct answer was "blue" and not "green". If a correct answer was given, a new word appeared on the screen; if the answer was incorrect the same word remained on the screen. Subjects were rewarded with $£ 0.10$ for each correct answer.
} 
trade-offs implied in the 16 games of the Conflict treatment should in principle also be willpower-depleting.

Of course, an ancillary assumption for our test is that the induced depletion of willpower is large enough to produce a detectable effect given the statistical power of the experiment. ${ }^{14}$ Thus, our design includes a series of elements aimed at strengthening the effect and hence maximizing the chances of detection. First, based on the evidence that the extent to which willpower is depleted is positively related to the duration of the depleting task (Vohs et al. 2008; Hagger et al. 2010), we had dictators face 16 decision problems, each time with different payoffs, so that they were forced to reconsider their choice each time a new game was presented to them. ${ }^{15}$ Moreover, we chose to decrease dictator-recipient anonymity and to have recipients interact with dictators throughout part one in order to reduce social distance between dictators and recipients and create a starker conflict between altruism and self-interest. ${ }^{16}$

In order to test whether we were successful in creating a perceivable conflict between altruistic and self-interested motives in the Conflict treatment, we included in the post-experimental questionnaire, as a manipulation check, two questions asking dictators to rate the extent to which they found the dictator game choices "hard" and "uncomfortable". ${ }^{17}$ Dictators in the Conflict treatment reported that choices in the dictator games were harder and more uncomfortable relative to dictators in NoConflict (hard: mean 3.07, s.d. 2.64 vs. mean 0.84, s.d. 1.75; discomfort: mean 4.12 , s.d. 3.26 vs. mean 1.05, s.d. 1.90). For both questions, we find that responses are significantly different across the two treatments (Wilcoxon-Mann-Whitney tests; hard: $p<0.001$; discomfort: $p<0.001){ }^{18}$ This suggests that dictators in the Conflict treatment may have indeed perceived a stronger motivational conflict than dictators in NoConflict. In Sect. 3.3, we test whether the (perceived) stronger

\footnotetext{
14 As we discuss later, given our sample size, we are powered to detect effects of size 0.40 or larger in terms of Cohen's $d$. The effects reported in the depleting literature are quite large. Vohs et al. (2008), for instance, report an average effect of $d=0.93$ across their 5 lab experiments on the willpower-depleting effects of choosing among small household products.

15 Payoffs were manipulated to vary: (1) the dictator's endowment (either GBP 10, 12 or 16); (2) the opportunity cost of making the choice that most benefited the recipient; (3) whether an equal split of money was available in the choice set; and (4) whether making the own payoff-maximizing choice reduced joint payoffs.

16 Decreasing anonymity has been shown to significantly increase giving in previous dictator-game experiments (e.g., Bohnet and Frey 1999; Charness and Gneezy 2008). Dictator giving has also been shown to increase when recipients interact with dictators (e.g., Yamamori et al. 2007, 2008). In our experiment, we reduced anonymity by making subjects type their first name on their computer at the beginning of part one. This was then shown to the person they were paired with in part one. Moreover, we forced dictators to wait after each decision until the recipient they were paired with had been shown the dictator's decision and had confirmed that they had seen it (and the dictator was notified about this).

17 These items were: "Overall, how hard was it to choose between option A and option B in the 16 situations of Part 1?", and "Overall, to what extent did you experience discomfort in making your choices in the 16 situations of Part 1?". Responses were collected on a scale from 0 ("not at all") to 10 ("very much").

18 All tests reported in this section use the individual as the independent unit of observation and therefore are based on 99 dictators per treatment.
} 


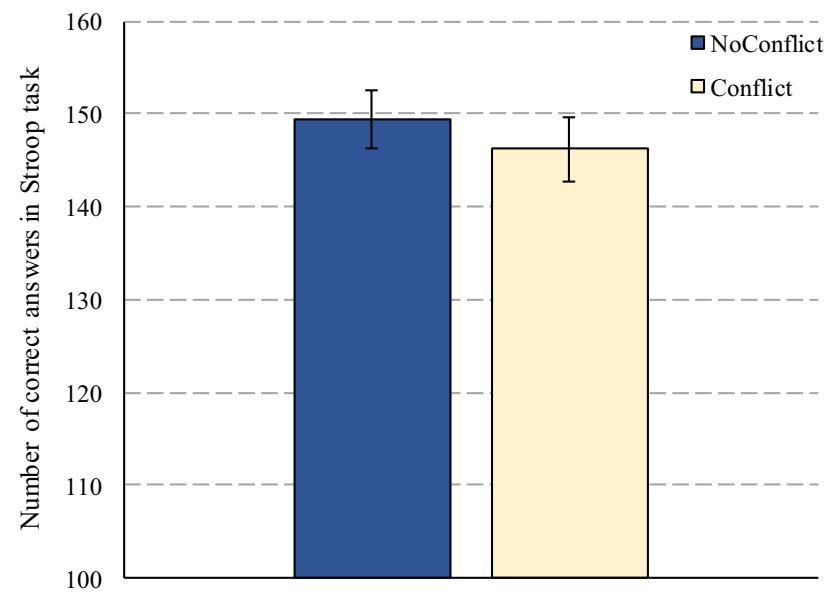

Fig. 3 Performance in the Stroop task, by treatment. Note: Bars indicate 95\% confidence intervals computed as $\mu \pm 1.96 * S E^{\mu}$ where $\mu$ is the estimated mean, $S E^{\mu}$ is its standard error, and 1.96 is the $\mathrm{z}$-score for the 97.5 percentile point of the normal distribution

conflict resulted in a more severe depletion of willpower as measured by dictators' Stroop task performance across the two treatments.

\subsection{Experimental procedures}

The experiment was programmed in z-Tree (Fischbacher 2007) and was conducted at the University of Nottingham using students from a wide range of disciplines recruited through the online recruitment system ORSEE (Greiner 2015). We have 396 subjects in total across 13 sessions, equally divided between the two treatments. Thus, our analysis is based on 99 dictators per treatment. This implies that we can detect effects of size 0.40 or larger (Cohen's $d$ ) with $80 \%$ power and $5 \%$ probability of a type-I error, using a two-sided Wilcoxon-Mann-Whitney test.

We report a detailed description of the procedures used in the experiment in Appendix B in the OSM and reproduce the experimental instructions in Appendix C. We paid subjects using a random incentive lottery system. At the end of each session, one of the two parts of the experiment was selected at random and subjects were paid according to their earnings from the selected part. If part one was selected, one of the 16 games was chosen at random and subjects were paid according to their earnings in that game. Sessions lasted approximately $50 \mathrm{~min}$ and earnings ranged between GBP0 and GBP19, averaging GBP11.81 (s.d. 4.77).

\subsection{Dictators' performance in the Stroop task}

Figure 3 shows the average number of correct answers in the Stroop task by dictators in the Conflict and NoConflict treatments. Dictators in Conflict gave fewer correct answers compared to NoConflict (Conflict: mean 146.21, s.d. 17.67; NoConflict: 
mean 149.44, s.d. 15.82). The resulting effect size (measured as Cohen's $d$ ) is -0.192 . The difference in performance is not statistically significant according to a Wilcoxon-Mann-Whitney test $(p=0.157)$. An OLS regression (reported in Appendix D in the OSM) confirms that the difference in performance remains insignificant after controlling for a number of observable characteristics of the subjects (including gender) and of the decision setting. ${ }^{19}$

\section{Discussion and conclusions}

In this paper, our aim was to probe the validity of a dual-system approach to altruistic behavior, by testing the hypothesis that trade-offs between self-interest and altruism trigger a conflict between our "fast", intuitive System 1 and our "slower", more deliberative System 2. We performed a meta-analysis of the existing literature on the relation between altruism and intuition/deliberation and found that the manipulations used in previous experiments to promote the intuitive system at the expense of the deliberative system (using ego depletion tasks, cognitive load, time pressure or priming) have an overall effect on altruism that is very close to, and not significantly different from, zero.

Can this aggregate null result be due to the fact that the relation between altruism and our two systems is genuinely heterogeneous across different subgroups and decision situations, as some researchers have suggested? We find little evidence that this may be the case. We first run a mediator analysis based on the existing literature and consider a number of potential mediators of the relation between intuition and altruism (including mediators previously suggested in the literature, such as gender, the stakes of the experiment, or the frame of the task). We find that none of the mediators included in the analysis play a significant role in explaining the mixed results in existing studies. One possible exception is the frame of the task, for which we find evidence of a mediating effect in some specifications of the analysis, but not in others.

We then designed and ran a new experiment that allowed us to probe the validity of dual-system theories of altruism without being vulnerable to the presence of unobserved and/or unanticipated heterogeneity in the relation between altruism and intuition. We argue that, if trade-offs between altruism and self-interest trigger

\footnotetext{
19 Another possible source of heterogeneity, that may weaken the aggregate effect, is the strength of the conflict between self-interest and altruistic concerns that subjects may have experienced during the dictator games. Subjects who have no concern for others and are exclusively motivated by self-interest (or vice versa subjects who have no concern for their self-interest and are exclusively motivated by altruism) may have experienced little or no motivational conflict and depletion of willpower during the dictator games. It is difficult, however, to identify this subgroup of dictators in our sample, since the choices in the dictator games are not indicative of whether or not the decision-maker has experienced a motivational conflict in making those choices. For example, observing an own payoff-maximizing choice in a game does not reveal whether this has been made by an entirely self-interested dictator, who experienced no conflict in making such choice, or by an other-regarding dictator who was conflicted in her decision but ultimately opted for the selfish option. In Appendix D we report an analysis based on the selfreported perception of conflict experienced in the dictator games, and find no evidence that this moderates the treatment effect in our experiment.
} 
a conflict between the intuitive and deliberative systems, then being exposed to these trade-offs should be willpower-depleting. We do not find evidence that this is the case. Directionally, the effect is in line with the hypothesis: subjects who were exposed to trade-offs between altruism and self-interest perform worse on a task that requires willpower than subjects who were not exposed to such trade-offs. However, we cannot reject the null that the two groups perform similarly. ${ }^{20}$

Overall, the combination of evidence from the meta-study and the new experiment suggests that choices that involve trade-offs between altruism and self-interest do not trigger any strong conflict between intuition and deliberation. This could be because, in the realm of altruistic behavior, the decision processes governed by the intuitive and deliberative systems may actually both lead to the same outcome for any given individual. That is, the two systems are not actually in conflict when it comes to making these type of decisions, and hence their outcome is the same. Alternatively, the null results reported in the literature and in our new experiment could mean that the lens of dual-system models does not extend to altruistic behavior. In either case, our study offers little support for the notion that, in the domain of altruistic choices, the individual must spend cognitive resources to override the intuitive impulse when the person wants to take a choice favored by the deliberative system.

Acknowledgements We thank Valerio Capraro, John Duffy, Dirk Engelmann, Johannes Lohse, Fabio Tufano, Roberto Weber, two anonymous referees, and participants at the CeDEx Brownbag seminar, the 2015 Inaugural RES Symposium of Junior Researchers, and the 2015 ESA European meeting, for helpful comments. We thank Carlos Alos-Ferrer, Valerio Capraro, Manja Gärtner, Zack Grossman, Eliran Halali, Karen Evelyn Hauge, Guy Itzchakov, Agne Kajackaite, Judd Kessler, Michał Krawczyk, Johannes Lohse, Kellen Mrkva, Jonathan Schulz, and Eirik Strømland for sharing the data of their studies with us. This work was supported by the University of Nottingham and the British Academy \& Leverhulme Trust (grant number SG140436). The paper was previously circulated under the title: "Do Tradeoffs between Self-interest and Other-Regarding Preferences Cause Willpower Depletion?".

Open Access This article is licensed under a Creative Commons Attribution 4.0 International License, which permits use, sharing, adaptation, distribution and reproduction in any medium or format, as long as you give appropriate credit to the original author(s) and the source, provide a link to the Creative Commons licence, and indicate if changes were made. The images or other third party material in this article are included in the article's Creative Commons licence, unless indicated otherwise in a credit line to the material. If material is not included in the article's Creative Commons licence and your intended use is not permitted by statutory regulation or exceeds the permitted use, you will need to obtain permission directly from the copyright holder. To view a copy of this licence, visit http://creativecommons.org/licen ses/by/4.0/.

\section{References}

Achtziger, A., Alós-Ferrer, C., \& Wagner, A. K. (2015). Money, depletion, and prosociality in the dictator game. Journal of Neuroscience, Psychology, and Economics, 8(1), 1-14.

\footnotetext{
${ }^{20}$ Of course, it is possible that an effect is actually present in our data-but it is smaller than our study is powered to detect (we are powered to detect effects of size 0.4 or larger). The estimated size of the effect in our new experiment is -0.192 . Detecting such an effect with $80 \%$ power would require re-running our experiment with a sample of about 450 dictators per treatment.
} 
Andersen, S., Gneezy, U., Kajackaite, A., \& Marx, J. (2018). Allowing for reflection time does not change behavior in dictator and cheating games. Journal of Economic Behavior \& Organization, 145, 24-33.

Balafoutas, L., Kerschbamer, R., \& Oexl, R. (2018). Distributional preferences and ego depletion. Journal of Neuroscience, Psychology, and Economics, 11(3), 147-165.

Banker, S., Ainsworth, S. E., Baumeister, R. F., Ariely, D., \& Vohs, K. D. (2017). The sticky anchor hypothesis: Ego depletion increases susceptibility to situational cues. Journal of Behavioral Decision Making, 30(5), 1027-1040.

Baumeister, R. F., Vohs, K. D., \& Tice, D. M. (2007). The strength model of self-control. Current Directions in Psychological Science, 16(6), 351-355.

Benjamin, D. J., Brown, S. A., \& Shapiro, J. M. (2013). Who is 'behavioral'? Cognitive ability and anomalous preferences. Journal of the European Economic Association, 11(6), 1231-1255.

Bohnet, I., \& Frey, B. S. (1999). Social distance and other-regarding behavior in dictator games: Comment. American Economic Review, 89(1), 335-339.

Bonett, D. G. (2015). Interval estimation of standardized mean differences in paired-samples designs. Journal of Educational and Behavioral Statistics, 40(4), 366-376.

Bouwmeester, S., et al. (2017). Registered replication report: Rand, greene, and nowak (2012). Perspectives on Psychological Science, 12(3), 527-542.

Burger, N., Charness, G., \& Lynham, J. (2011). Field and online experiments on self-control. Journal of Economic Behavior \& Organization, 77(3), 393-404.

Capraro, V. (2019). The dual-process approach to human sociality: A review. SSRN discussion paper.

Capraro, V., Corgnet, B., Espín, A. M., \& Hernán-González, R. (2017). Deliberation favours social efficiency by making people disregard their relative shares: Evidence from USA and India. Royal Society Open Science, 4(2), 160605.

Carter, E. C., Kofler, L. M., Forster, D. E., \& McCullough, M. E. (2015). A series of meta-analytic tests of the depletion effect: Self-control does not seem to rely on a limited resource. Journal of Experimental Psychology: General, 144(4), 796-815.

Charness, G., \& Gneezy, U. (2008). What's in a name? Anonymity and social distance in dictator and ultimatum games. Journal of Economic Behavior \& Organization, 68(1), 29-35.

Chen, F., \& Krajbich, I. (2018). Biased sequential sampling underlies the effects of time pressure and delay in social decision making. Nature Communications, 9(1), 1-10.

Cornelissen, G., Dewitte, S., \& Warlop, L. (2011). Are social value orientations expressed automatically? Decision making in the dictator game. Personality and Social Psychology Bulletin, 37(8), 1080-1090.

De Haan, T., \& Van Veldhuizen, R. (2015). Willpower depletion and framing effects. Journal of Economic Behavior \& Organization, 117, 47-61.

Deck, C., \& Jahedi, S. (2015). The effect of cognitive load on economic decision making: A survey and new experiments. European Economic Review, 78, 97-119.

Dreber, A., Fudenberg, D., Levine, D. K., \& Rand, D. G. (2016). Self-control, social preferences and the effect of delayed payments. Working paper, Washington University in St. Louis, St. Louis. Available at SSRN: http://ssrn.com/abstract=2477454. Retrieved February 14, 2020.

Fischbacher, U. (2007). Z-tree: Zurich toolbox for ready-made economic experiments. Experimental Economics, 10(2), 171-178.

Friehe, T., \& Schildberg-Hörisch, H. (2017). Self-control and crime revisited: Disentangling the effect of self-control on risk taking and antisocial behavior. International Review of Law and Economics, 49, 23-32.

Fritz, C. O., Morris, P. E., \& Richler, J. J. (2012). Effect size estimates: Current use, calculations, and interpretation. Journal of Experimental Psychology: General, 141(1), 2-18.

Gärtner, M. (2018). The prosociality of intuitive decisions depends on the status quo. Journal of Behavioral and Experimental Economics, 74, 127-138.

Gelman, A., \& Loken, E. (2013). The garden of forking paths: Why multiple comparisons can be a problem, even when there is no 'fishing expedition' or 'p-hacking' and the research hypothesis was posited ahead of time. WP, Department of Statistics, Columbia University.

Greiner, B. (2015). Subject pool recruitment procedures: Organizing experiments with ORSEE. Journal of the Economic Science Association, 1(1), 114-125.

Grolleau, G., Sutan, A., Harbi, S. E., \& Jedidi, M. (2018). Do we need more time to give less? Experimental evidence from Tunisia. Bulletin of Economic Research, 70(4), 400-409. 
Grossman, Z., \& Van der Weele, J. J. (2017). Dual-process reasoning in charitable giving: Learning from non-results. Games, 8(3), 36.

Hagger, M., Wood, C., Stiff, C., \& Chatzisarantis, N. (2010). Ego depletion and the strength model of self-control: A meta-analysis. Psychological Bulletin, 136(4), 495-525.

Halali, E., Bereby-Meyer, Y., \& Ockenfels, A. (2013). Is it all about the self? The effect of self-control depletion on ultimatum game proposers. Frontiers in Human Neuroscience, 7, 1-8.

Hauge, K. E., Brekke, K. A., Johansson, L.-O., Johansson-Stenman, O., \& Svedsäter, H. (2016). Keeping others in our mind or in our heart? Distribution games under cognitive load. Experimental Economics, 19(3), 562-576.

Higgins, J., \& Green, S. (Eds.). (2011). Cochrane handbook for systematic reviews of interventions. 5.1.0. The Cochrane Collaboration. Retrieved February 14, 2020 from www.handbook.cochrane.org.

Itzchakov, G., Uziel, L., \& Wood, W. (2018). When attitudes and habits don't correspond: Self-control depletion increases persuasion but not behavior. Journal of Experimental Social Psychology, 75, $1-10$.

Janssen, L., Fennis, B. M., Pruyn, A. T. H., \& Vohs, K. D. (2008). The path of least resistance: Regulatory resource depletion and the effectiveness of social influence techniques. Journal of Business Research, 61(10), 1041-1045.

Jarke, J., \& Lohse, J. (2016). I'm in a hurry, I don't want to know! The effects of time pressure and transparency on self-serving behavior. WiSo-HH working paper series no. 32.

Kahneman, D. (2002). Maps of bounded rationality: A perspective on intuitive judgment and choice. Nobel prize lecture, 8, 351-401.

Kahneman, D. (2011). Thinking, fast and slow. New York: Farrar, Straus and Giroux.

Kessler, J. B., \& Meier, S. (2014). Learning from (Failed) replications: Cognitive load manipulations and charitable giving. Journal of Economic Behavior \& Organization, 102, 10-13.

Kinnunen, S. P., \& Windmann, S. (2013). Dual-processing altruism. Frontiers in Psychology, 4, 193.

Krawczyk, M., \& Sylwestrzak, M. (2018). Exploring the role of deliberation time in non-selfish behavior: The double response method. Journal of Behavioral and Experimental Economics, 72, 121-134.

Kuhn, M. A., Kuhn, P., \& Villeval, M. C. (2014). Self control and intertemporal choice: Evidence from glucose and depletion interventions. CESifo working paper no. 4609.

Kvarven, A., Strømland, E., Wollbrant, C. E.-P., Andersson, D., Johannesson, M., Tinghög, G., Västfjäll, D., \& Myrseth, K. O. R. (2019). The intuitive cooperation hypothesis revisited: A meta-analytic examination of effect-size and between-study heterogeneity. MetaArXiv preprint, https://doi. org/10.31222/osf.io/kvzg3.

Lipsey, M. W., \& Wilson, D. B. (2001). Practical meta-analysis. Thousand Oaks: Sage Publications Inc.

Loewenstein, G., \& O'Donoghue, T. (2007). The heat of the moment: Modeling interactions between affect and deliberation. Carnegie Mellon University Department of Social and Decisions Sciences unpublished working paper. Available at http://citeseerx.ist.psu.edu/viewdoc/download?doi=10.1.1. 217.4310\&rep=rep1\&type=pdf. Retrieved February 14, 2020.

MacLeod, C. M. (1991). Half a century of research on the Stroop effect: An integrative review. Psychological Bulletin, 109(2), 163-203.

Merkel, A. L., \& Lohse, J. (2019). Is fairness intuitive? An experiment accounting for subjective utility differences under time pressure. Experimental Economics, 22(1), 24-50.

Moore, D. A., \& Loewenstein, G. (2004). Self-interest, automaticity, and the psychology of conflict of interest. Social Justice Research, 17(2), 189-202.

Morey, R. D., Hoekstra, R., Rouder, J. N., Lee, M. D., \& Wagenmakers, E.-J. (2016). The fallacy of placing confidence in confidence intervals. Psychonomic Bulletin \& Review, 23(1), 103-123.

Mrkva, K. (2017). Giving, fast and slow: reflection increases costly (but not uncostly) charitable giving. Journal of Behavioral Decision Making, 30(5), 1052-1065.

Muraven, M., \& Baumeister, R. F. (2000). Self-regulation and depletion of limited resources: Does selfcontrol resemble a muscle? Psychological Bulletin, 126(2), 247.

Rand, D. G. (2016). Cooperation, fast and slow: Meta-analytic evidence for a theory of social heuristics and self-interested deliberation. Psychological Science, 27(9), 1192-1206.

Rand, D. G. (2019). Intuition, deliberation, and cooperation: Further meta-analytic evidence from 91 experiments on pure cooperation. SSRN discussion paper. https://doi.org/10.2139/ssrn.3390018.

Rand, D. G., Brescoll, V. L., Everett, J. A., Capraro, V., \& Barcelo, H. (2016). Social heuristics and social roles: Intuition favors altruism for women but not for men. Journal of Experimental Psychology: General, 145(4), 389-396. 
Schulz, J. F., Fischbacher, U., Thöni, C., \& Utikal, V. (2014). Affect and fairness: Dictator games under cognitive load. Journal of Economic Psychology, 41, 77-87.

Small, D. A., Loewenstein, G., \& Slovic, P. (2007). Sympathy and callousness: The impact of deliberative thought on donations to identifiable and statistical victims. Organizational Behavior and Human Decision Processes, 102(2), 143-153.

Spears, D. (2011). Economic decision-making in poverty depletes behavioral control. The B.E. Journal of Economic Analysis \& Policy, 11(1), 72.

Strombach, T., Margittai, Z., Gorczyca, B., \& Kalenscher, T. (2016). Gender-specific effects of cognitive load on social discounting. PLOS ONE, 11(10), e0165289.

Strømland, E., \& Torsvik, G. (2019). Intuitive prosociality: Heterogeneous treatment effects or false positive? Unpublished manuscript. Retrieved February 14, 2020 from https://osf.io/hrx2y

Stroop, R. J. (1935). Studies of interference in serial verbal reactions. Journal of Experimental Psychology, 18, 643-662.

Tinghög, G., Andersson, D., Bonn, C., Johannesson, M., Kirchler, M., Koppel, L., et al. (2016). Intuition and moral decision-making: The effect of time pressure and cognitive load on moral judgment and altruistic behavior. PLOS ONE, 11(10), e0164012.

Verschuere, B., Köbis, N. C., Bereby-Meyer, Y., Rand, D., \& Shalvi, S. (2018). Taxing the brain to uncover lying? Meta-analyzing the effect of imposing cognitive load on the reaction-time costs of lying. Journal of Applied Research in Memory and Cognition, 7, 462-469.

Vohs, K. D., Baumeister, R. F., Schmeichel, B. J., Twenge, J. M., Nelson, N. M., \& Tice, D. M. (2008). Making choices impairs subsequent self-control: A limited-resource account of decision making, self-regulation, and active initiative. Journal of Personality and Social Psychology, 94(5), 883-898.

Vosgerau, J., Simonsohn, U., Nelson, L. D., \& Simmons, J. P. (2018). Internal meta-analysis makes falsepositives easier to produce and harder to correct. SSRN working paper.

Wang, J., Novemsky, N., Dhar, R., \& Baumeister, R. F. (2010). Trade-offs and depletion in choice. Journal of Marketing Research, 47(5), 910-919.

Xu, H., Bègue, L., \& Bushman, B. J. (2012). Too fatigued to care: Ego depletion, guilt, and prosocial behavior. Journal of Experimental Social Psychology, 48(5), 1183-1186.

Yamamori, T., Kato, K., Kawagoe, T., \& Matsui, A. (2007). Online chat leads to fairness in dictator games. Available at https://www.researchgate.net/publication/228456615_Online_chat_leads_to_ fairness_in_dictator_games. Retrieved February 14, 2020.

Yamamori, T., Kato, K., Kawagoe, T., \& Matsui, A. (2008). Voice matters in a dictator game. Experimental Economics, 11(4), 336-343.

Zaki, J., \& Mitchell, J. P. (2013). Intuitive prosociality. Current Directions in Psychological Science, 22(6), 466-470.

Publisher's Note Springer Nature remains neutral with regard to jurisdictional claims in published maps and institutional affiliations.

\section{Affiliations}

\section{Hanna Fromell ${ }^{1} \cdot$ Daniele Nosenzo $^{2,3}$ (D) $\cdot$ Trudy Owens $^{3}$}

Hanna Fromell

h.c.fromell@rug.nl

Trudy Owens

trudy.owens@nottingham.ac.uk

1 Department of Economics, Econometrics, and Finance, University of Groningen, Groningen, The Netherlands

2 Luxembourg Institute of Socio-Economic Research (LISER), 11 Porte des Sciences, 4366 Esch-sur-Alzette, Luxembourg

3 School of Economics, University of Nottingham, Nottingham, UK 